\title{
Analysis and Control of MMC-HVDC Under Unbalanced Voltage Conditions
}

\begin{abstract}
A vector current controller based on quasi proportional resonant (PR) in $\alpha \beta$ stationary reference frame is used to control the positive and negative sequence currents uniformly. Through analyzing the power characteristics under unbalanced grid conditions, control strategies to suppress negative sequence current and active power ripples are realized without the additional transformation between $\alpha \beta$ and d q reference frame. A more general method is proposed to analyze the circulating current features and sequence components; then a circulating current controller is designed based on quasi PR controller. The traditional voltage balancing algorithm is also improved to reduce switching times by adjusting the voltage sorting frequency according to the capacitor voltage standard deviation (CVSD).
\end{abstract}

Dept. of Electric Eng., North China Electric Power University, BaoDing, China

Keywords:

modular multilevel converter(MMC); quasi proportional resonant(Quasi PR); circulating current; capacitor voltage standard deviation; voltage balance.

\section{Introduction}

The modular multilevel converter (MMC) as a new topology for multilevel converters with potential for medium and high voltage applications has drawn increasing attention in recent years [1]-[3]. Because MMC is based on the synthesis of ac voltage from several different voltage levels on the dc bus, the output waveform quality will be greatly improved as the number of voltage levels on the dc side increase[4]-[10].

The authors are with the Status Key Laboratory of Alternate Electrical Power System with Renewable Energy Sources, North China Electric Power University, Baoding 071001, China. (e-mail:zhangjianpo@126.com). 
Ac system can't avoid failures. For dealing with unbalanced grid conditions, a dual vector current control scheme(DVCC) including positive and negative sequence vector current controllers was applied to MMC based HVDC system[6],[11]. Because there are four vector current controllers and the current needs to be decomposed into positive and negative sequence component, the control system becomes relatively complex. Although PR controller was used to control the negative and positive sequence currents in voltage source converter (VSC) under unbalanced grid condition in [12]-[14], the current reference is calculated in the $\mathrm{d} \mathrm{q}$ rotational reference frame and then transformed into ac reference signal, the transformation between $\mathrm{d} \mathrm{q}$ and $\alpha \beta$ reference frame is required. Another resonant scalar control to avoid voltage and current sequences extraction is also discussed in [15]; however, it needs a voltage disturbance characterization module to determine the type of encountered voltage sag and the phases with maximum and minimum residual voltages to calculate the current amplitude.

Although there are many literatures about circulating current and its controlling strategies, the analysis of circulating current characteristics and sequence components is based on a prerequisite that ac and dc current are equally split by the upper, down arm and the three phase arms respectively [16]-[19], or a virtual current only flowing through the upper and down arms is defined beforehand [12]. As for how to handle the circulating current there are two common types of controlling methods. One is based on $d \mathrm{q}$ synchronous rotational frame [16], the other is based on three or two stationary frame [13],[17]. Reference [16] proposed a method of controlling circulating currents under balanced voltage condition through transforming the circulating current to dc component in the $\mathrm{d}$ q negative sequence rotational frame, but this method can't completely suppress all the sequence components of circulating currents under unbalanced voltage conditions. Reference [13] and [17] respectively propose a circulating current controlling method based on PR and proportional integral resonant (PIR) in a b c and $\alpha \beta$ stationary frame. However, a high pass filter to extract the double base frequency component from the arm current is required. The filters may influence the dynamic performance of the controller.

Capacitors voltage balance as a core of valve control is another challenge associated with multilevel 
converters. The voltage balancing algorithm by sorting capacitor voltages is proposed in [7],[20],[21], sub modules (SM) are sorted at a given frequency and triggered according to the direction of arm current, this process will cause some unnecessary switching status change.

In order to address these aforementioned issues of MMC-HVDC, a quasi proportional resonant controller is used to control the positive and negative sequence current uniformly and the current reference is calculated directly in the $\alpha \beta$ stationary reference frame without transformation between different reference frame. The quantitative relationship between the ac current, dc link current and circulating current is derived by solving the arm voltage and current equation. The sequence components of arm current are also analyzed under unbalanced voltage condition. A nearest level modulation (NLM) strategy in conjunction with a voltage balancing algorithm based on variable sorting frequency is also improved to reduce unnecessary switching status change.

The rest of this paper is organized as following. Section II introduces the generic structure for MMC. The vector current controllers based on quasi PR, the arm current and circulating current are also analyzed. In addition, capacitor voltage standard deviation is defined to evaluate the voltage balancing degree and realize variable sorting frequency balancing algorithm of NLM. The negative sequence current, active power ripples suppressing methods with over current limiter are discussed for MMC-HVDC applications in section III. Section IV presents the simulation results of these two post fault strategies, followed by concluding remarks in section $\mathrm{V}$.

\section{System structure and Control model}

Fig.1 shows the equivalent circuit configuration of MMC in HVDC applications. MMC consists of six arms where each arm contains $\mathrm{N}$ series connected, nominally identical, half-bridge sub modules. The relationship between grid and valve side voltage under three phase static reference frame is expressed as following (1), where $\mathrm{j} \in(\mathrm{a}, \mathrm{b}, \mathrm{c}), \mathrm{L}$ is the arm inductance to restrict the dc link short current, $\mathrm{L}_{\mathrm{T}}$ is the transformer leakage inductance. 


$$
\left(L_{\mathrm{T}}+0.5 L\right) \frac{d i_{j}}{d t}=u_{c j}-u_{s j}
$$

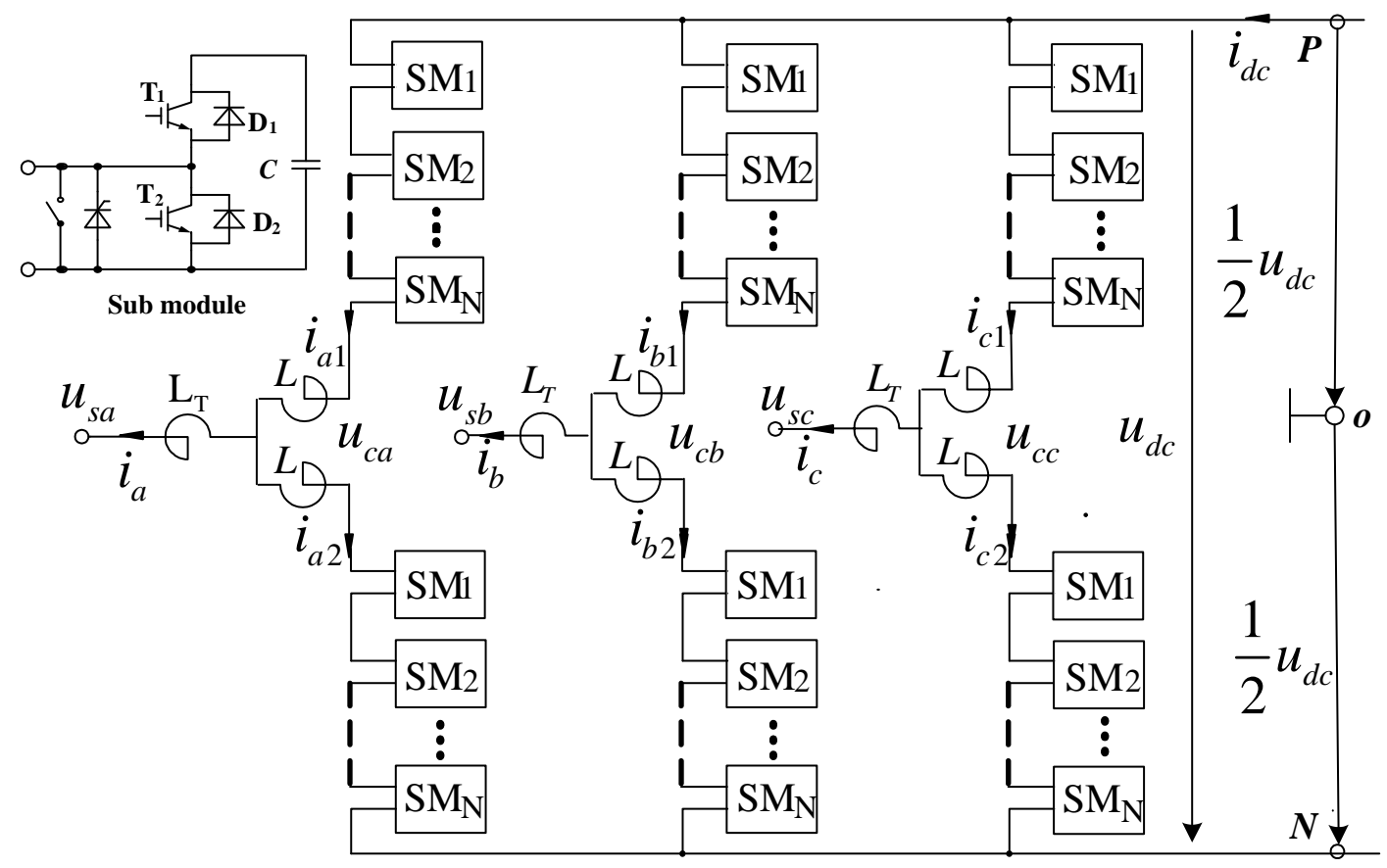

Fig.1. Equivalent circuit of MMC

Equation (2) in $\alpha \beta$ stationary reference frame can be deduced from (1), where $u_{\mathrm{sa}} u_{\mathrm{s} \beta} u_{\mathrm{ca}}$ and $u_{\mathrm{c} \beta}$ are grid side and valve side base frequency voltages in the $\alpha \beta$ stationary frame, $i_{\mathrm{a}}$ and $i_{\beta}$ are current in $\alpha \beta$ stationary frame.

$$
\left\{\begin{array}{l}
\left(L_{\mathrm{T}}+0.5 L\right) \frac{d i_{\alpha}}{d t}=u_{c \alpha}-u_{s \alpha} \\
\left(L_{\mathrm{T}}+0.5 L\right) \frac{d i_{\beta}}{d t}=u_{c \beta}-u_{s \beta}
\end{array}\right.
$$

The input instantaneous active $\mathrm{P}_{\mathrm{s}}$ and reactive power $\mathrm{Q}_{\mathrm{s}}$ of $\mathrm{MMC}$ can be calculated in $\alpha \beta$ stationary reference frame by (3) according to [22].

$$
\left\{\begin{array}{l}
P_{\mathrm{s}}=1.5\left(u_{s \alpha} i_{\alpha}+u_{s \beta} i_{\beta}\right) \\
Q_{\mathrm{s}}=-1.5\left(u_{s \alpha} i_{\beta}-u_{s \beta} i_{\alpha}\right)
\end{array}\right.
$$

\subsection{Proportional Resonant Controller}


It is known that voltages and currents of MMC in $\alpha \beta$ stationary reference frame are ac signals, so it is difficult to achieve ideal ac signal control with conventional PI controller in the synchronous rotational reference frame. PR controller with an infinite gain at specific frequency can achieve zero steady status errors in tracking ac signals [23]-[24], so the stationary reference frame PR controller can achieve the same performance as a synchronous rotational frame controller without the need for coordinate transformation of inputs and outputs of controller.

An approximation (4) is given by quasi-PR controller. Where $\mathrm{Kp}$ is proportional coefficient, $\mathrm{K}_{\mathrm{R}}$ is resonant coefficient, $\omega_{0}$ is resonant frequency. Compared with ideal PR controller, the cutoff frequency $\omega_{c}$ can be set appropriately to expand controller bandwidth so as to decrease the sensitivity to signal frequency variation.

$$
G_{P R}(S)=K_{P}+2 K_{R} \omega_{c} \frac{S}{S^{2}+2 \omega_{c} S+\omega_{0}^{2}}
$$

The control equation of vector current controller is expressed as (5).

$$
\left\{\begin{array}{l}
u_{c \alpha}=u_{s \alpha}-G_{P R}\left(i_{\alpha}^{*}-i_{\alpha}\right) \\
u_{c \beta}=u_{s \beta}-G_{P R}\left(i_{\beta}^{*}-i_{\beta}\right)
\end{array}\right.
$$

\subsection{Optimized Capacitor Voltage Balancing Control}

The modulation methods used in multilevel converters can be classified as pulse width modulation (PWM) methods with higher switching frequency and staircase modulation methods at lower switching frequency [25]-[26]. NLM as one representative method of staircase modulation is taken in this paper.

Because there are several switching combinations for a specified number of SM, voltage balancing control is required for MMC. The traditional capacitor voltage sorting balance is adopted by many literatures on MMC. Capacitor voltages in one arm are sorted in descend order at a constant sorting

frequency (CSF) and specified SMs are switched on or off at every switching instance according to the sorting results and direction of arm currents [7]. 
The main problem associated with aforementioned method is high switching frequency as balancing algorithm switches SM according to their respective capacitor voltages at every control period. To solve this problem, a new balancing method to reduce switching frequency was proposed in [27]. However, voltage band must be set, and the band is relatively difficult to choose objectively. Another similar voltage balancing algorithms is that all the capacitor voltage is multiplied by a factor (greater or less 1 ) to change the sorting result [28]. The author in [7] adopted a reduced sorting frequency voltage balancing algorithm through only sorting those SMs whose operation status are off when SM number of on status changes so as to reduce switching frequency, but the switching interval time is not equal during a period, so the earlier SM is switched on, the larger or smaller its voltage will become.

The objective of capacitor voltage balancing control should not only keep capacitor voltages fluctuating within a same level but also reduce unnecessary SM status change. So the traditional capacitor voltage balance control can be optimized by adjusting the sorting frequency which is defined as variable sorting frequency (VSF) voltage balance to distinguish from the traditional voltage balance.

Standard deviation is used in this paper to denote the quantity that all the capacitors voltage of an arm departure their means value, so the voltage unbalanced level can be calculated in terms of capacitor voltage standard deviation.

Firstly SM capacitor voltage of each arm is defined as an array (6), where $m \in\left(\begin{array}{ll}1 & 2\end{array}\right), 1$ and 2 denote upper and down arm.

$$
u_{j m_{-} c}=\left\{u_{j m_{-} c 1}, u_{j m_{-} c 2} \ldots, u_{j m_{-} c N}\right\}
$$

CVSD can be calculated by (7), where $u_{\mathrm{e}}$ is the capacitor voltage means value.

$$
\delta\left(u_{c}\right)=\sqrt{\frac{1}{N} \sum_{k=1}^{N}\left(u_{j m_{-} c k}-u_{e}\right)^{2}}
$$

Then CVSD is normalized by capacitor voltage means value. 


$$
\delta^{*}\left(u_{c}\right)=\sqrt{\frac{1}{N} \sum_{k=1}^{N}\left(\frac{u_{j m_{-} c k}-u_{e}}{u_{e}}\right)^{2}}
$$

Normally, the range of capacitor voltage variation has to be limited to about $10 \%$ of its rated value, so the $\delta^{*}\left(u_{c}\right) \leqq 10 \%$.

The basic principles of the variable sorting frequency voltage balancing algorithm (VSF-VB) are defined as following.

When $\sigma^{*}\left(u_{\mathrm{c}}\right)$ is smaller than a preset value, the whole capacitor voltages of an arm differ little from each other, so VSF-VB doesn't sort capacitor voltage and keeps original sorting sequence to reduce unnecessary SMs status change.

When $\sigma^{*}\left(u_{\mathrm{c}}\right)$ is greater than the preset value, it means that the whole capacitor voltages of an arm differ large from each other, so VSF-VB sorts capacitor voltage and displaces the original sorting sequence with the new result, then SMs will be witched on or off in the new order. Compared with the conventional method, the proposed VSF-VB can reduce the average switching frequency and total switching losses through reducing unnecessary SM status change.

\subsection{Circulating Current Analysis}

Circulating currents $\left(i_{j_{-}}\right.$circle $)$caused by MMC working mechanism and capacitor voltage fluctuations flow through arms are illustrated as Fig.2 which will distort the sinusoidal arm current and increase the rated current of power devices. Circulating current components and their characters will be analyzed as following.

In Fig.2, $u_{\mathrm{j} 1}$ and $u_{\mathrm{j} 2}$ represent the output voltage of the upper and down arm SMs of phase $j, u_{\mathrm{j} \_ \text {ref }}$ represents the instantaneous modulation reference waveform. 


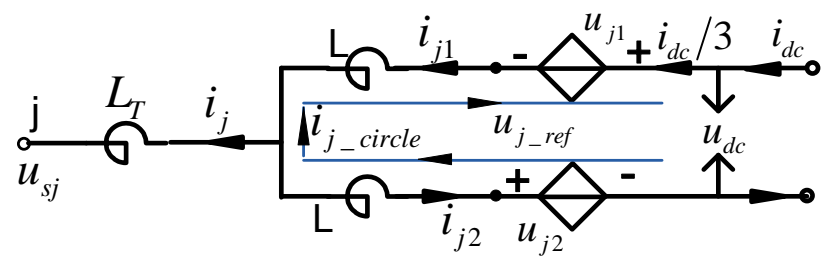

Fig.2. Single arm equivalent circuit of phase $j$

The upper arm voltage $u_{\mathrm{j} 1}$ and down arm voltage $u_{\mathrm{j} 2}$ are defined as (9).

$$
\left\{\begin{array}{l}
u_{j 1}=\sum_{k=1}^{n} u_{j 1} c k \\
u_{j 2}=\sum_{k=1}^{m} u_{j 2_{-} c k}+L \frac{d i_{j 1}}{d t} \\
d t
\end{array}\right.
$$

The $\mathrm{k}$ capacitor voltage at $t$ is expressed as (10).

$$
\left\{\begin{array}{l}
u_{j 1} c k \\
u_{j 2_{2} c k}(t)=u_{j 1} c k \\
u_{j 2_{-} c k}\left(t_{0}\right)+1 / C \int_{t_{0}}^{t} i_{j 2} d \tau
\end{array}\right.
$$

Equation (11) can be built according to Fig.1.

$$
U_{j}+\sum_{k=1}^{n} \frac{1}{C} \int_{t_{0}}^{t} i_{j 1} d \tau+\sum_{k=1}^{m} \frac{1}{C} \int_{t_{0}}^{t} i_{j 2} d \tau+L \frac{d\left(i_{j 1}+i_{j 2}\right)}{d t}=U_{d c}
$$

$U_{j}$ is expressed as following.

$$
U_{j}=\sum_{k=1}^{n} u_{j 1_{-} c k}\left(t_{0}\right)+\sum_{k=1}^{m} u_{j 2_{-} c k}\left(t_{0}\right)
$$

According to the relationship $i_{j}=i_{j 1}-i_{j 2}, N=n+m$, (11) can be rewritten as (13).

$$
U_{d c}=U_{j}+\frac{N}{C} \int_{t_{0}}^{t} i_{j 1} d \tau-\frac{m}{C} \int_{t_{0}}^{t} i_{j} d \tau+2 L \frac{d i_{j 1}}{d t}-L \frac{d i_{j}}{d t}
$$

Presumably, $u_{j_{-} r e f}=U_{m} \sin (\omega t+\theta)$ and $i_{j}=I_{m} \sin \omega t$, then $\mathrm{m}$ (the down arm SM number )is calculated as following, where $\lambda=U_{\mathrm{m}} / U_{\mathrm{dc}}$.

$$
m=\frac{0.5 U_{d c}+U_{m} \sin (\omega t+\theta)}{(1 / N) U_{d c}}=\frac{N}{2}+N \lambda \sin (\omega t+\theta)
$$

Substituting $m$ into (13) and derivation, then (15) is obtained, where $I_{0}=I_{m} \cos \omega t_{0}$. 


$$
\frac{2 L C}{N} \frac{d^{2} i_{j 1}}{d t^{2}}+i_{j 1}-\left(\frac{1}{2}-\frac{\omega^{2} L C}{N}\right) I_{m} \sin \omega t-\lambda I_{0} \cos (\omega t+\theta)+\lambda I_{m} \cos (2 \omega t+\theta)=0
$$

According to $(16), i_{\mathrm{dc}}=2 / 3 \times\left(\lambda I_{m} \cos \theta\right)$.

$$
\left\{\begin{array}{c}
P=1.5 U_{m} I_{m} \cos \theta \\
P=U_{d c} i_{d c}
\end{array}\right.
$$

Then the upper arm current equation is as (17) when the number of sub modules $\mathrm{N}$ is very large.

$$
\begin{aligned}
& i_{j 1}=\left(\frac{1}{2}-\frac{\omega^{2} L C}{N}\right) I_{m} \sin \omega t-\frac{\lambda I_{m} \cos (2 \omega t+\theta)}{2}-\frac{2 L C}{N} \frac{d^{2} i_{j 1}}{d t^{2}}+\frac{i_{d c}}{3} \\
& i_{j 1} \approx \frac{1}{2} I_{m} \sin \omega t-\frac{1}{2} \lambda I_{m} \cos (2 \omega t+\theta)+\frac{1}{3} i_{d c}
\end{aligned}
$$

The down arm current can be obtained as (18).

$$
\begin{aligned}
& i_{j 2}=-\frac{2 L C}{N} \frac{d^{2} i_{j 2}}{d t^{2}}-\left(\frac{1}{2}-\frac{\omega^{2} L C}{N}\right) I_{m} \sin \omega t-\frac{\lambda I_{m} \cos (2 \omega t+\theta)}{2}+\frac{i_{d c}}{3} \\
& i_{j 2} \approx-\frac{1}{2} I_{m} \sin \omega t-\frac{1}{2} \lambda I_{m} \cos (2 \omega t+\theta)+\frac{1}{3} i_{d c}
\end{aligned}
$$

It can be seen from (17) (18), there are three kinds of current in the arm current, the ac current $i_{j}$ is distributed equally between the upper and down arm, what is more, the dc current is also divided equally by the three phase arms. Although there are no harmonic components in ac voltage and current, the arm currents also contain 2nd harmonics caused by capacitor voltage fluctuation. Under balanced grid condition, 2nd current in the three arms are also symmetrical, because the total sum of them is zero, they will only flow in the arms and have no effect on the dc or ac current, so this kind of current is defined as circulating current. Under unbalanced voltage conditions, the voltage and current can be defined as following.

$$
\left\{\begin{array}{c}
u_{j_{-} r e f}=U_{m+} \sin \left(\omega t+\theta_{j_{+}}\right)+U_{m-} \sin \left(\omega t+\theta_{j_{-}}\right) \\
i_{j}=I_{m+} \sin \left(\omega t+\Phi_{j+}\right)+I_{m-} \sin \left(\omega t+\Phi_{j_{-}}\right)
\end{array}\right.
$$

Then $\mathrm{m}$ can be also expressed as following, where $\lambda_{+}=U_{\mathrm{m}+} / U_{\mathrm{dc}}, \lambda_{-}=U_{\mathrm{m}-} / U_{\mathrm{dc}}$.

$$
m=\left(0.5 U_{d c}+u_{j_{-} r e f}\right) /\left((1 / N) U_{d c}\right)=0.5 N+N \lambda_{+} \sin \left(\omega t+\theta_{j+}\right)+N \lambda_{-} \sin \left(\omega t+\theta_{j_{-}}\right)
$$


The upper arm and down arm currents are given by (20) according to the above analysis.

$$
\left\{\begin{array}{c}
i_{j 1} \approx 0.5 i_{j}+i_{j_{-} d c}-i_{j_{-} \text {circle }} \\
i_{j 2} \approx-0.5 i_{j}+i_{j_{-} d c}-i_{j_{-} \text {circle }}
\end{array}\right.
$$

The dc component $i_{\mathrm{j} \_\mathrm{dc}}$ in (20) is expressed as (21).

$$
i_{j_{-} d c}=\lambda_{+} I_{m+} \cos \left(\Phi_{j+}-\theta_{j+}\right)+\lambda_{+} I_{m-} \cos \left(\Phi_{j-}-\theta_{j+}\right)+\lambda I_{m+} \cos \left(\Phi_{j+}-\theta_{j-}\right)+\lambda I_{m-} \cos \left(\Phi_{j-}-\theta_{j-}\right)
$$

The circulating current positive, negative and zero sequence components in (22) are expressed as

$$
\begin{gathered}
i_{j_{-} \text {circle }}=i_{j_{-} \text {circle }+}+i_{j_{-} \text {circle- }}+i_{j_{-} \text {circle } 0} \\
\left\{\begin{array}{c}
i_{j_{-} \text {circle }+}=\lambda_{-} I_{m-} \cos \left(2 \omega t+\Phi_{j-}-\theta_{j-}\right) \\
i_{j_{-} \text {circle- }}=\lambda_{+} I_{m+} \cos \left(2 \omega t+\Phi_{j+}-\theta_{j+}\right) \\
i_{j_{-} \text {circle } 0}=\lambda_{+} I_{m-} \cos \left(2 \omega t+\Phi_{j-}-\theta_{j+}\right)+\lambda_{-} I_{m+} \cos \left(2 \omega t+\Phi_{j+}-\theta_{j-}\right)
\end{array}\right.
\end{gathered}
$$

Although voltage $\left(u_{\mathrm{j} \_ \text {ref }}\right)$ and current $\left(i_{\mathrm{j}}\right)$ have negative sequences components under unbalanced grid condition, the circulating current can still be decomposed into positive, negative and zero sequence components with $100 \mathrm{~Hz}$.

Equation (24) as following can be obtained by adding (20).

$$
i_{j_{-} a v g}=0.5\left(i_{j 1}+i_{j 2}\right)=i_{j_{-} d c}-i_{j_{-}} \text {circle }
$$

Because $i_{j_{\_} \text {avg }}$ as upper arm and down arm average current has dc current and circulating current according to (24), a circulating current controller with Quasi-PR $\left(\omega_{0}=200 \pi\right)$ can be designed to control these sequences uniformly.

\section{Power analysis and reference calculation}

\subsection{Instantaneous Real and Reactive Power Analysis}

Under unbalanced grid conditions (e.g., asymmetrical fault), the voltage and current in $\alpha \beta$ can be expressed as (25). 


$$
\left\{\begin{array}{c}
u_{s \alpha}=u_{s \alpha+}+u_{s \alpha-} \\
u_{s \beta}=u_{s \beta+}+u_{s \beta-} \\
i_{\alpha}=i_{\alpha+}+i_{\alpha-} \\
i_{\beta}=i_{\beta+}+i_{\beta-}
\end{array}\right.
$$

The apparent power inputs at the point of common coupling (PCC) can be calculated as (26).

$$
S=1.5\left(u_{s \alpha}+j u_{s \beta}\right)\left(i_{\alpha}+j i_{\beta}\right)^{*}=\left(P_{0}+P_{2}\right)+j\left(Q_{0}+Q_{2}\right)
$$

Where $P_{0}, Q_{0}, P_{2}, Q_{2}$ are given by (27)-(29), $u_{\mathrm{s} \alpha+}, u_{\mathrm{s} \alpha-} u_{\mathrm{s} \beta+}, u_{\mathrm{s} \beta}$-are positive and negative sequence voltage, $i_{\mathrm{s} \alpha+}, i_{\mathrm{s} \alpha-} i_{\mathrm{s} \beta+}, i_{\mathrm{s} \beta-}$ are positive and negative sequence current, $P_{0}, Q_{0}$ are average active and reactive power value, $P_{2}, Q_{2}$ are the active and reactive power fluctuating component with $100 \mathrm{~Hz}$.

$$
\begin{aligned}
& \left\{\begin{array}{l}
P_{0}=1.5\left(u_{s \alpha+} i_{\alpha+}+u_{s \beta+} i_{\beta+}+u_{s \alpha-} i_{\alpha-}+u_{s \beta-} i_{\beta-}\right) \\
Q_{0}=1.5\left(u_{s \beta+} i_{\alpha+}-u_{s \alpha+} i_{\beta+}+u_{s \beta-} i_{\alpha-}-u_{s \alpha-} i_{\beta-}\right)
\end{array}\right. \\
& P_{2}=1.5\left(u_{s \alpha+} i_{\alpha-}+u_{s \beta+} i_{\beta-}+u_{s \alpha-} i_{\alpha+}+u_{s \beta-} i_{\beta+}\right) \\
& Q_{2}=1.5\left(u_{s \beta+} i_{\alpha-}-u_{s \alpha+} i_{\beta-}+u_{s \beta-} i_{\alpha+}-u_{s \alpha-} i_{\beta+}\right)
\end{aligned}
$$

Because there are negative sequence currents and power ripples, control strategy under steady status must be adjusted to improve system fault through ability. There are usually two different power control strategies for conventional converters under unbalanced conditions. The one is to eliminate negative sequence current components and keep ac currents balanced; the other is to eliminate the active power double base frequency ripples.

\subsection{Two Post Fault Control Strategies}

Under balanced grid conditions, the control object is to keep the system output active and reactive power following its command, the current reference can be calculated through the following two methods: indirect method as (30) $\left(i_{d}^{*} i_{q}^{*}\right.$ can be obtained from the outer loop voltage control) and direct method as (31) $\left(Q^{*} P^{*}\right.$ are the power reference value) [22].

$$
\left[\begin{array}{c}
i_{\alpha}^{*} \\
i_{\beta}^{*}
\end{array}\right]=\left[\begin{array}{cc}
\cos (\omega t) & -\sin (\omega t) \\
\sin (\omega t) & \cos (\omega t)
\end{array}\right]\left[\begin{array}{c}
i_{d}^{*} \\
i_{q}^{*}
\end{array}\right]
$$




$$
\left[\begin{array}{c}
i_{\alpha}^{*} \\
i_{\beta}^{*}
\end{array}\right]=\left[\begin{array}{cc}
u_{s \alpha} & u_{s \beta} \\
u_{s \beta} & -u_{s \alpha}
\end{array}\right]^{-1} \times\left[\begin{array}{c}
P^{*} \\
Q^{*}
\end{array}\right]
$$

Under unbalanced grid condition, the control strategy 1 to control negative sequence current is designed by setting $i_{\mathrm{a}-}=0, i_{\beta-}=0$ in (27) as following (32).

$$
\left[\begin{array}{l}
i_{\alpha+}^{*} \\
i_{\beta+}^{*}
\end{array}\right]=\left[\begin{array}{cc}
u_{s \alpha+} & u_{s \beta+} \\
u_{s \beta+} & -u_{s \alpha+}
\end{array}\right]^{-1} \times\left[\begin{array}{l}
P^{*} \\
Q^{*}
\end{array}\right]
$$

The control strategy 2 is designed to suppress the double base frequency ripples of the three phase active power input to the MMC, this can be done by setting $P_{2}=0$ in (28) as (33).

$$
\left[\begin{array}{l}
i_{\alpha+}^{*} \\
i_{\beta+}^{*} \\
i_{\alpha-}^{*} \\
i_{\beta-}^{*}
\end{array}\right]=\left[\begin{array}{cccc}
u_{s \alpha+} & u_{s \beta+} & u_{s \alpha-} & u_{s \beta-} \\
u_{s \beta+} & -u_{s \alpha+} & u_{s \beta-} & -u_{s \alpha-} \\
u_{s \alpha-} & u_{s \beta-} & 0 & 0 \\
0 & 0 & u_{s \alpha+} & u_{s \beta+}
\end{array}\right]^{-1} \times\left[\begin{array}{c}
P^{*} \\
Q^{*} \\
0 \\
0
\end{array}\right]
$$

Through above analysis, the current references to control negative current and active power ripples are calculated directly by (32) (33) without reference frame transformation in [12]-[14].

Control strategy 1 is mainly to suppress the negative sequence current so as to keep ac grid current balanced; but there are ripples in the total active and reactive power to the ac grid, what is more the power of three phase arms will differ from each other because of unbalanced voltage. Control strategy 2 is to keep the whole active power transported to the ac grid constant, so the power of three phase arm is almost balanced, while this can result in three phase ac currents asymmetric, the fault phase current will increase more than the other two normal phases.

When grid faults are serious (e.g., metallic short), while the power reference remains unchanged during fault, the over current problem will be caused according to (32) (33), so the over current limiter (OCL) must be considered to reduce the transmitted power. Because the current and voltage are ac signals in $\alpha \beta$ reference frame, the voltage amplitude is taken to design the OCL with respected to $u_{s \alpha}^{2}+u_{s \beta}^{2}=U_{m}^{2}$, the reactive power is set to zero for transmitting more active power. 
Firstly, the over current factor is defined as $\rho$, where $i_{j_{-} f a u l t}^{*}$ is the fault current reference, $i_{j_{-}}^{*}$ normal is the rated current command, where $j \in(\alpha \beta)$.

$$
\left\{\begin{array}{c}
i_{j_{-} \text {normal }}^{*}=P^{*} u_{s j} /\left(u_{s \alpha}^{2}+u_{s \beta}^{2}\right) \\
\rho=i_{j_{-} \text {fault }}^{*} / i_{j_{-} \text {normal }}^{*}
\end{array}\right.
$$

The amplitude of positive sequence and rated voltage is defined as $k$ to indicate the degree of voltage drop, while $\eta$ is used to represent the voltage imbalance degree. If $\eta$ is larger, the imbalance between three phase currents will be more serious to keep active power constant.

$$
\left\{\begin{array}{c}
k=\sqrt{\left(u_{s \alpha+}^{2}+u_{s \beta+}^{2}\right) /\left(u_{s \alpha}^{2}+u_{s \beta}^{2}\right)} \\
\eta=\sqrt{\left(u_{s \alpha-}^{2}+u_{s \beta-}^{2}\right) /\left(u_{s \alpha+}^{2}+u_{s \beta+}^{2}\right)}
\end{array}\right.
$$

Then current reference can be calculated as (36) for control strategy 1 , where $i_{j_{+}}^{*}=i_{j_{-} \text {fault }}^{*}$.

$$
i_{j+}^{*}=P^{*} u_{s j} / k\left(u_{s \alpha}^{2}+u_{s \beta}^{2}\right)
$$

$P_{o c l}^{*}$ (The revised active power reference when over current problem occurs) is defined as following.

$$
\left\{\begin{array}{c}
P_{o c l}^{*}=P^{*} \quad k \geq 1 / \rho \\
P_{o c l}^{*}=k \rho P^{*} \quad k<1 / \rho
\end{array}\right.
$$

While for control strategy 2 , the relationship between positive and negative voltage can be expressed as (38) ( $e^{-s t}$ denotes the phase angle delay).

$$
\left\{\begin{array}{l}
u_{s \alpha-}=\eta e^{-s t} u_{s \alpha+} \\
u_{s \beta-}=\eta e^{-s t} u_{s \beta+}
\end{array}\right.
$$

The current instruction can be calculated as (39), then the total current is expressed as (40), where

$$
\begin{gathered}
i_{j}^{*}=i_{j_{-} \text {fault }}^{*} \cdot \\
\left\{\begin{array}{l}
i_{j+}^{*}=P^{*} u_{s j+} /\left(u_{s \alpha+}^{2}+u_{s \beta+}^{2}-u_{s \alpha-}^{2}-u_{s \beta-}^{2}\right) \\
i_{j-}^{*}=P^{*} u_{s j-} /\left(u_{s \alpha+}^{2}+u_{s \beta+}^{2}-u_{s \alpha-}^{2}-u_{s \beta-}^{2}\right)
\end{array}\right. \\
i_{j}^{*}=i_{j+}^{*}+i_{j-}^{*}=\frac{P^{*} u_{s j}\left(1+\eta e^{-s t}\right)}{\left(1-\eta^{2}\right) k\left(u_{s \alpha}^{2}+u_{s \beta}^{2}\right)}
\end{gathered}
$$


Equation (41) can be also expressed as following.

$$
\dot{I}_{j}^{*}=\frac{P^{*} \dot{U}_{s j}(1+\eta \angle \theta)}{\left(1-\eta^{2}\right) k\left(u_{s \alpha}^{2}+u_{s \beta}^{2}\right)}
$$

The modulus value $I_{j}^{*}$ is expressed as

$$
I_{j}^{*}=\frac{P^{*} U_{s j} \sqrt{1+\eta^{2}+2 \eta \cos \theta}}{\left(1-\eta^{2}\right) k\left(u_{s \alpha}^{2}+u_{s \beta}^{2}\right)} \leq \frac{P^{*} U_{s j}}{(1-\eta) k\left(u_{s \alpha}^{2}+u_{s \beta}^{2}\right)}
$$

According to (42), $P_{o c l}^{*}$ is defined as (43)

$$
\left\{\begin{array}{c}
P_{o c l}^{*}=P^{*} \quad(1-\eta) k \geq 1 / \rho \\
P_{o c l}^{*}=(1-\eta) \rho k P^{*} \quad(1-\eta) k<1 / \rho
\end{array}\right.
$$

The whole control scheme including pole-level control, capacitor voltage balancing control (VBC) and circulating current control (CCC) is illustrated as Fig.3.

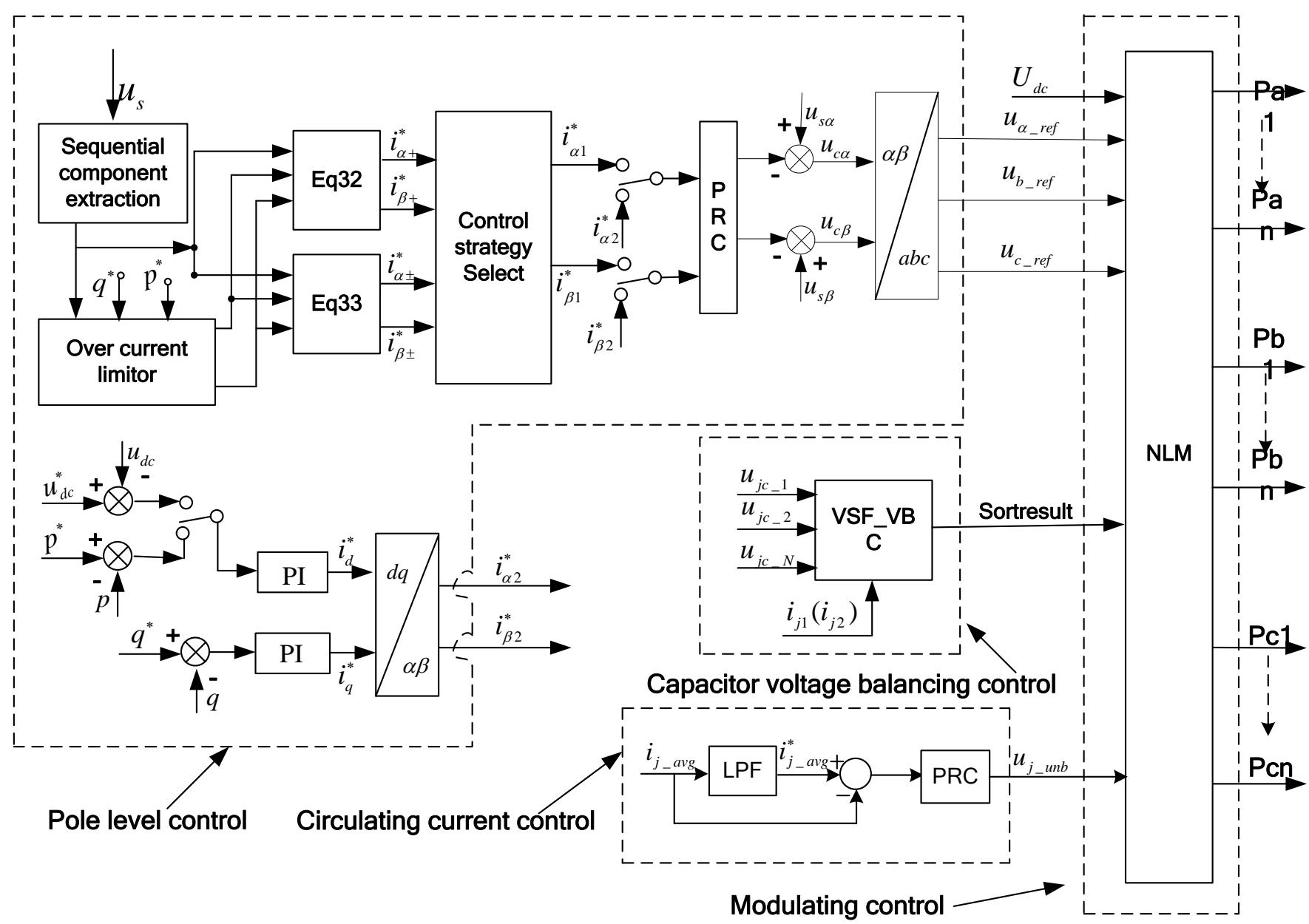

Fig.3. Whole controlling block diagram 
Pole-level control is to guarantee the system normal operation and realize the power and voltage control objectives, the VBC is to keep capacitor voltage balance and lower the additional switching loss, while the CCC can reduce the amplitude of arm current by suppressing the circulating current component, then the conduction loss will decrease. Both VBC and CCC belong to valve-level control; they have no effects on the system control objects as long as the system can operate normally. In order to reduce the CVSD and capacitor voltage ripples, CCC is enabled, while VBC is switched to constant sorting frequency voltage balancing control during the fault clearing period.

\section{Study Results}

\subsection{Study System}

The HVDC system of Fig.4 is simulated in the time domain PSCAD/EMTDC environment. MMC1 controls dc bus voltage and reactive power input to the converter, and their command are set as $400 \mathrm{kV}$ and 0 Mvar respectively. MMC2 regulates the real and reactive power inputs to the converter and their command are set as 400MW and 0Mvar respectively. The main circuit parameters are listed in Table I. A 21 level MMC-HVDC system is used to reduce the simulating time.

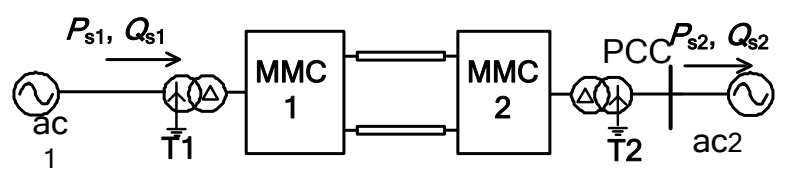

Fig.4. Two terminal model of simulation

Dc bus voltage must keep constant to guarantee the system operating properly, so if MMC1 fails to function, the control strategy of MMC2 must be changed to control dc bus voltage, then MMC1 control the power, so all the following simulations are carried out in the MMC2 side.

Table 1

Main circuit parameters 


\begin{tabular}{cccc}
\hline Parameters & Value & Parameters & Value \\
Rated dc voltage & $400 \mathrm{kV}$ & Rated active power & $400 \mathrm{MW}$ \\
AC system voltage & $210 \mathrm{kV}$ & Transformer ratio & $210 \mathrm{kV} / 220 \mathrm{kV}$ \\
Transformer leakage inductance & $0.1 \mathrm{pu}$ & Number of SM per arm & 20 \\
SM capacitor C & $3000 \mathrm{uF}$ & Arm inductance L & $0.1 \mathrm{pu}$ \\
SM capacitor voltage & $20 \mathrm{kV}$ & Length of DC cable & $100 \mathrm{~km}$ \\
\hline
\end{tabular}

\subsection{Verification of the VSF-VB}

To verify VSF-VB, SMs capacitors voltages in the upper arm of phase A are compared under CSF and VSF voltage balancing schemes.

As can be seen, CVSD of both schemes are within the limited degree (less than 10\%) in Fig.5. It is also shown that the VSF changes SM status only when CVSD is higher than the preset value (2\%), so CVSD is larger than that of CSF.

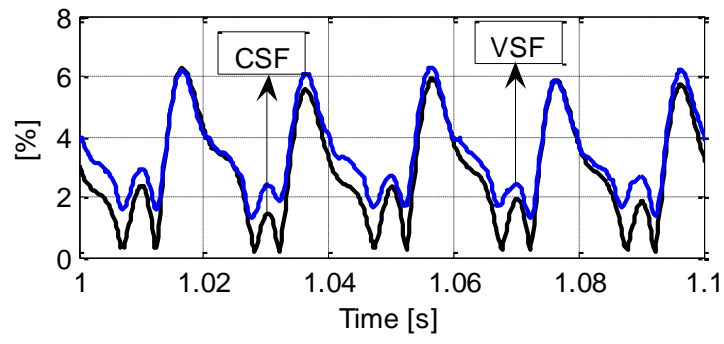

Fig.5. CVSD of VSF vs CSF of Phase A upper arm

From Table II, the average SM switching times of six arms are greatly reduced by VSF, and the switching loss can decrease accordingly (where 1and 2 denote upper and down arm respectively).

Table 2

Switching times of VSF and CSF

\begin{tabular}{|c|c|c|c|c|c|}
\hline & VSF/Times & CSF/Times & & VSF/Times & CSF/Times \\
\hline Phase A1 & 252 & 858 & Phase A2 & 253 & 856 \\
\hline Phase B1 & 251 & 836 & Phase B2 & 251 & 836 \\
\hline
\end{tabular}




\subsection{Analysis of Anti-voltage disturbances}

The stability and accuracy of control system will be affected when the grid voltage disturbance occurs; two simulating scenarios are designed as following to analyze system adaptation.

Firstly, the grid voltage frequency changes from $50 \mathrm{~Hz}$ to $40 \mathrm{~Hz}$ at $1 \mathrm{~s}$, then it increase from $50 \mathrm{~Hz}$ to $60 \mathrm{~Hz}$ at $1.15 \mathrm{~s}$, both of which last for 0.1s as shown in Fig.6(a). For the dual vector current control scheme, the cross decoupling item $(2 \pi \mathrm{fL})$ will change and the control system can't be decoupled completely; at the same time, the accuracy of the two coordinate transformation between (a b c) and (d q) may be affected. But for the PR there aren't such problems caused by decoupling items in the current inner controller and coordinate transformation between (a b c) and $(\alpha \beta)$, so PR has better anti-disturbance capacity. However, when the frequency of control signal deviates from the resonance point, the PR controller gain will decrease, which may affect the control accuracy. The affection can be seen from Fig.7(a) (b) that the current inner loop controller has some minor errors during frequency change, but the power outer loop controller is not affected as shown in Fig.7(d).

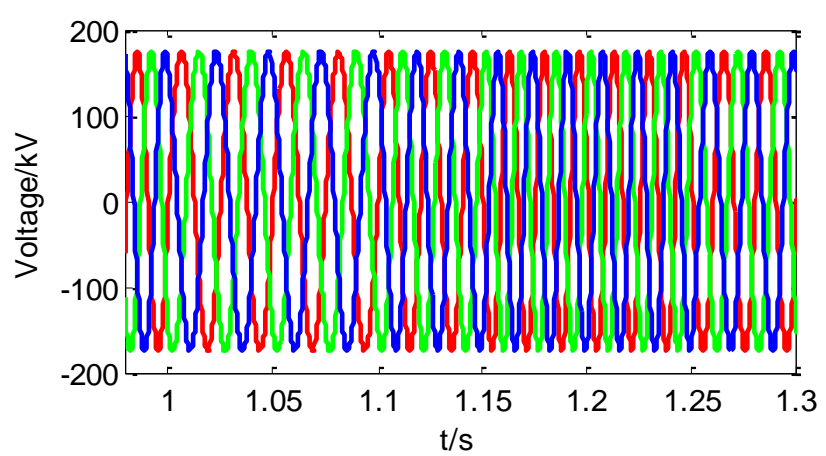

(a)

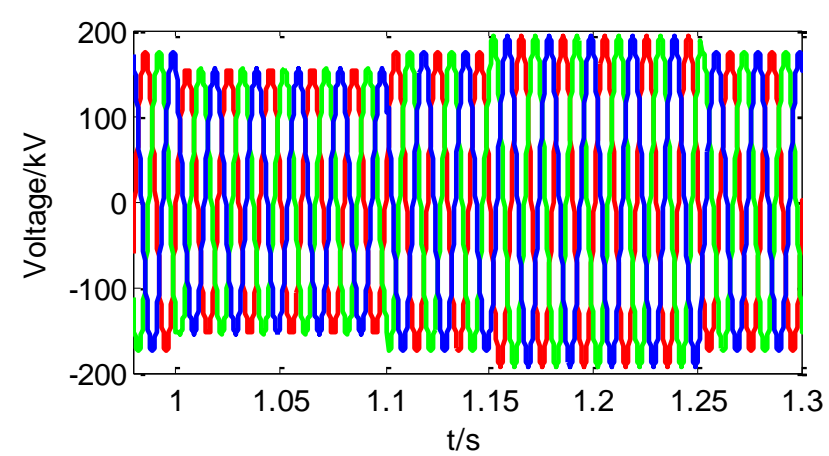

(b)

Fig.6. Waveform of grid voltage: (a) under frequency fluctuation, (b) under amplitude fluctuation. 


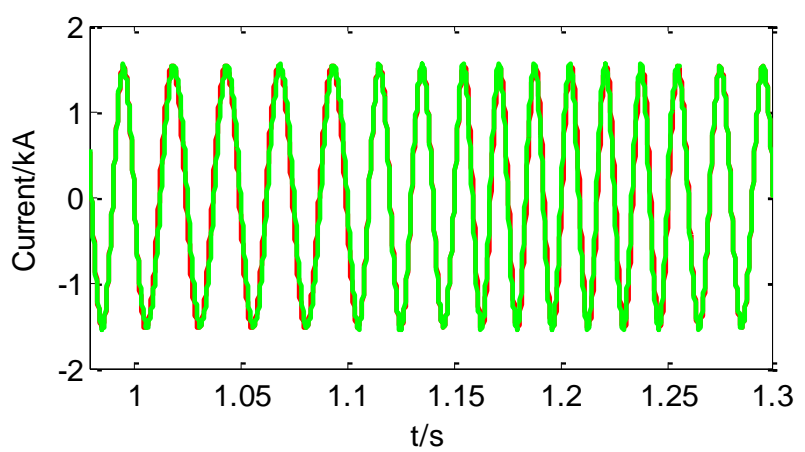

(a)

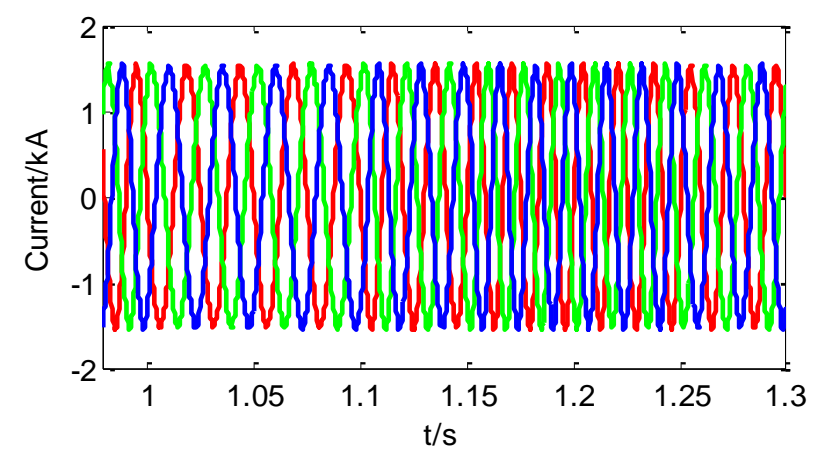

(c)

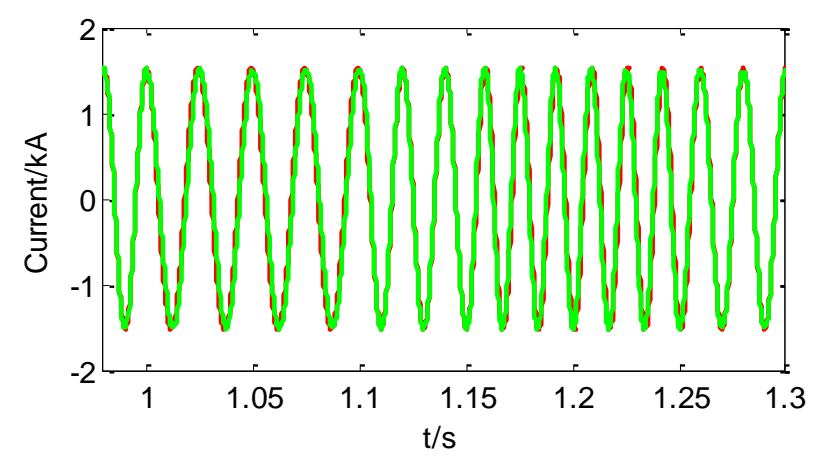

(b)

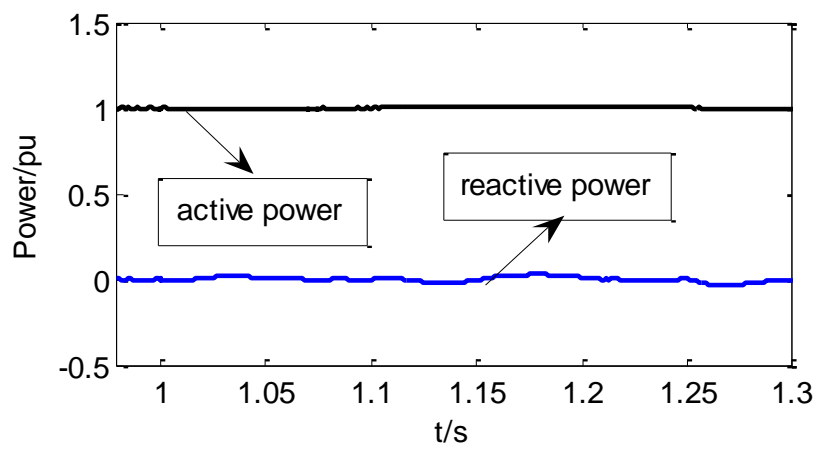

(d)

Fig.7. Waveform under grid frequency fluctuations: (a) $\alpha$ axis current, (b) $\beta$ axis current, (c) ac grid current, (d) active and reactive power.

In order to analyze the influences of grid voltage amplitude fluctuation, it firstly decreases from 210kVto $190 \mathrm{kV}$ at $1 \mathrm{~s}$, then it steps from $210 \mathrm{kV}$ to $230 \mathrm{kV}$ at $1.15 \mathrm{~s}$, both changes last for $0.1 \mathrm{~s}$ as shown in Fig.6(b). In order to ensure a constant power output, the three-phase ac current amplitude increases (decreases) to offset the voltage variation as illustrated in Fig.8(a). Voltage amplitude fluctuation does not affect the control precision, so the current inner loop can track without static error as shown in Fig.8(b)(c). However, according to the MMC working mechanism, when the ac voltage amplitude decreases, the modulation will decreases too, the corresponding upper and lower arm SM number during normal operation will be reduced as shown in Fig.8(e). On the other hand, it can be also seen from Fig.8(e) that increased modulation makes SM number in working condition increase which may cause over modulation problem if the voltage amplitude changes very large (In this case, the voltage variation is $\pm 20 \mathrm{kV}$ which is equal to a SM output voltage, the modulation under normal operation is 0.9 , so the over modulation problem can be avoid). 


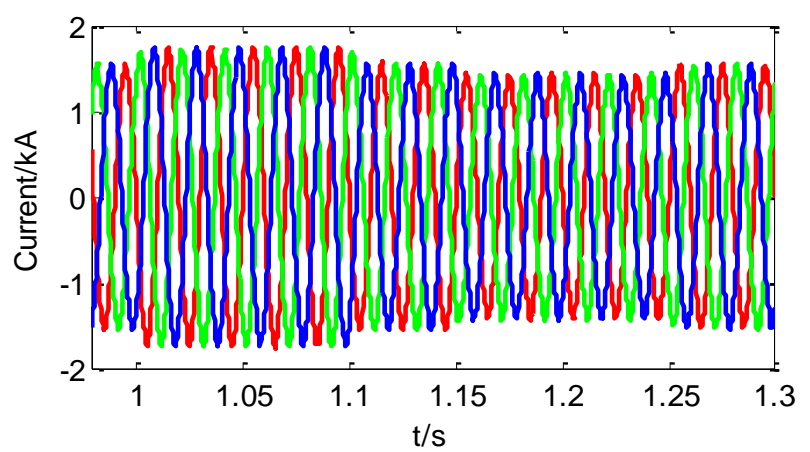

(a)

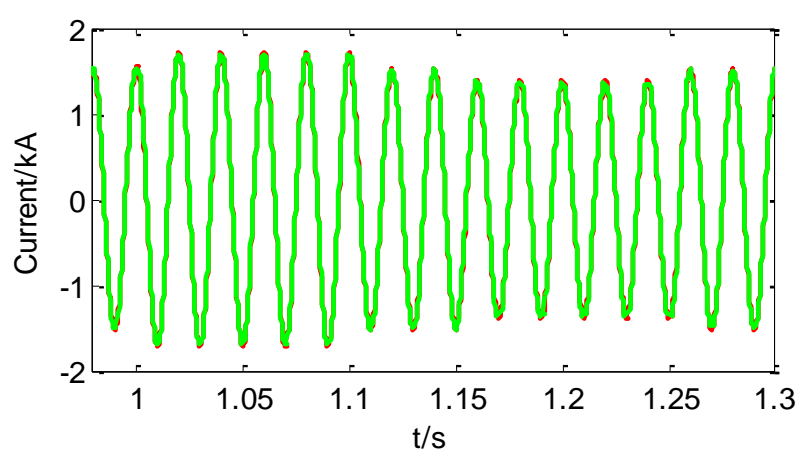

(c)

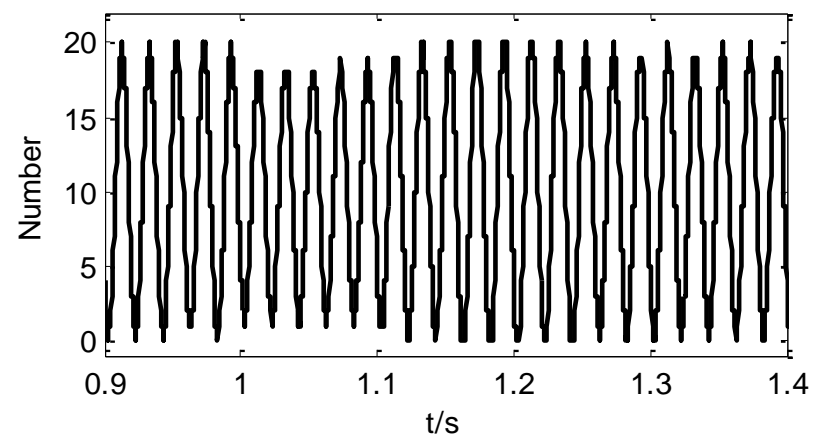

(e)

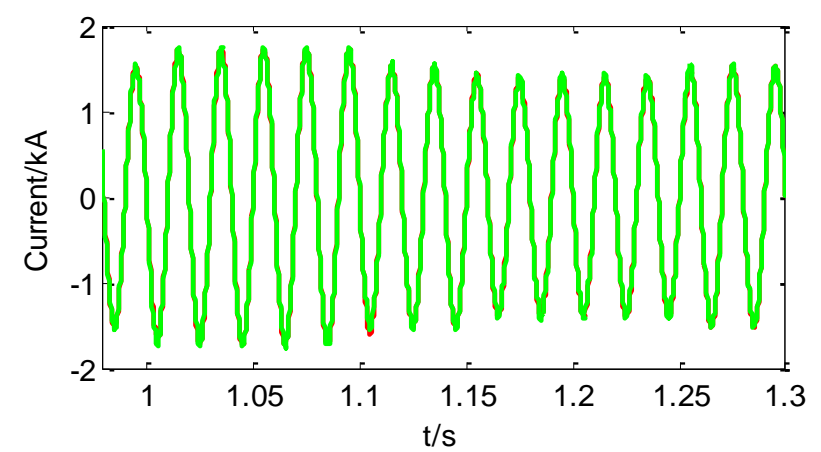

(b)

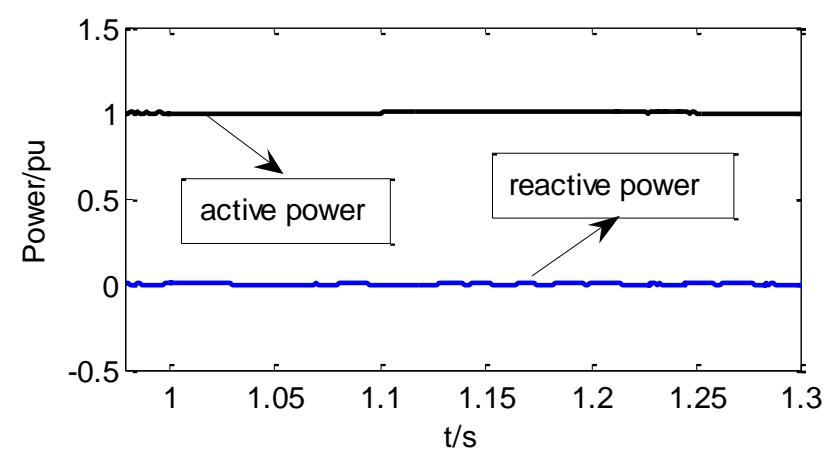

(d)

Fig.8. Waveform under grid voltage fluctuations: (a) ac grid current, (b) $\alpha$ axis current, (c) $\beta$ axis current, (d) active and reactive power, (e) SM number of phase A upper arm.

\subsection{Performance of the post fault strategies}

A single line to ground fault (SLG) is taken as an example to verify these strategies in this paper. SLG as Fig.9 occurring at 1.0s is imposed on PCC which lasts for $0.5 \mathrm{~s}$, and the control strategy is enabled after $0.05 \mathrm{~s}$, while circulating current control is enabled after $0.1 \mathrm{~s}$ to show its control effect. 


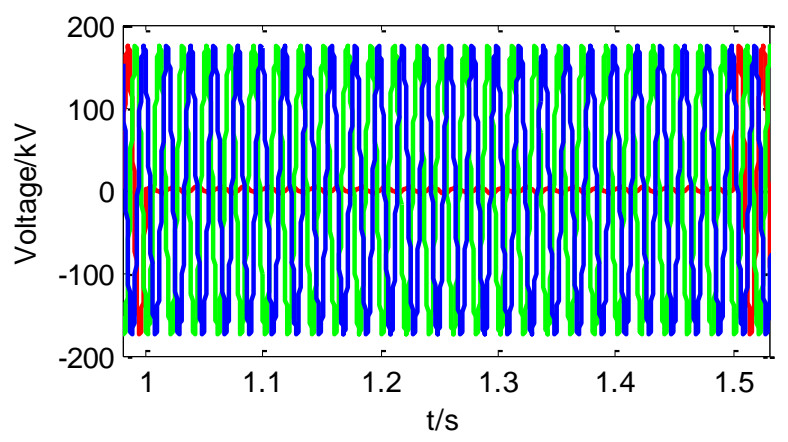

(a)

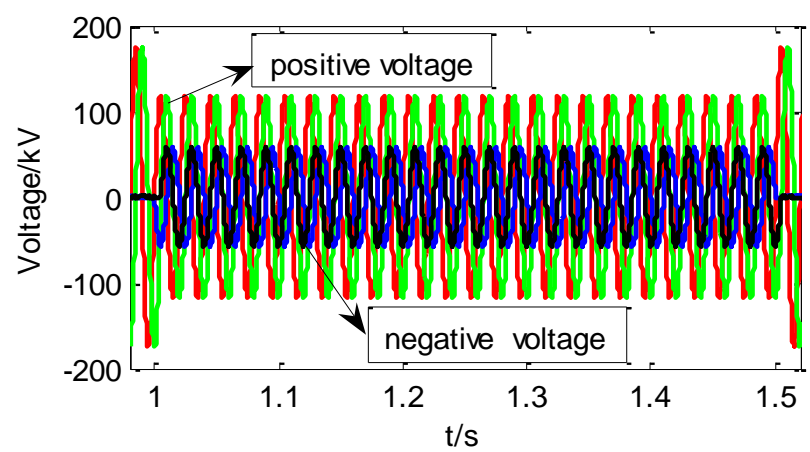

(b)

Fig.9. Waveform of grid voltage under SLG fault: (a) in a b c reference frame, (b) in $\alpha \beta$ reference frame.

\subsubsection{Control the Negative Sequence Current}

To keep ac side currents of MMC2 balanced during fault, control strategy 1 is adopted. The negative sequence current components are reduced to zero and ac currents of Fig. 4 keep balanced during SLG as shown in Fig.10(a). Because active power command keeps unchanged, ac currents also become higher than the rated value. What is more, negative sequence voltage remains, so there are ripples in the active and reactive power during fault as shown in Fig.10(b). SM capacitor voltages of phase A upper arm are illustrated in Fig.10(c), capacitor voltage ripples also increase under unbalanced conditions. The three phase $I_{\text {avg }}$ illustrated in Fig.10(d) shows that the fluctuation caused by circulating current also decreases correspondingly after the control is enabled, but they are different from each other during fault because the three phase ac active power are unbalanced. The control effect of DVCC as illustrated in Fig.10 (e) (f) shows that DVCC can control the negative sequence current, but there are some differences between DVCC and PR before the negative current control is enabled because of different capability of controlling ac and de signal. 


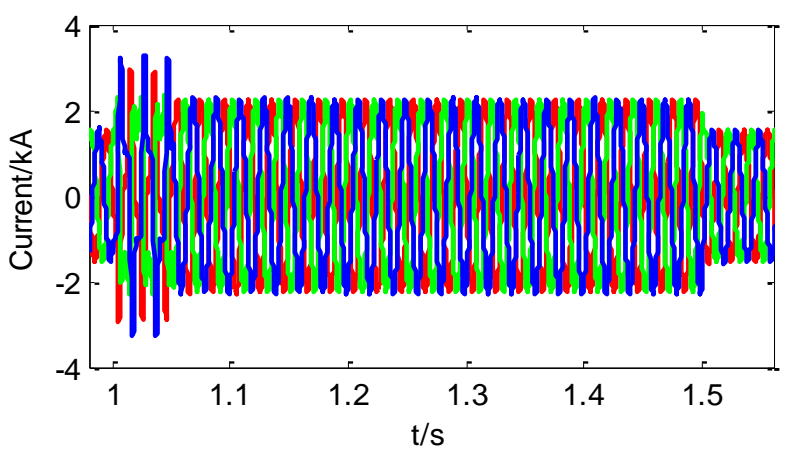

(a)

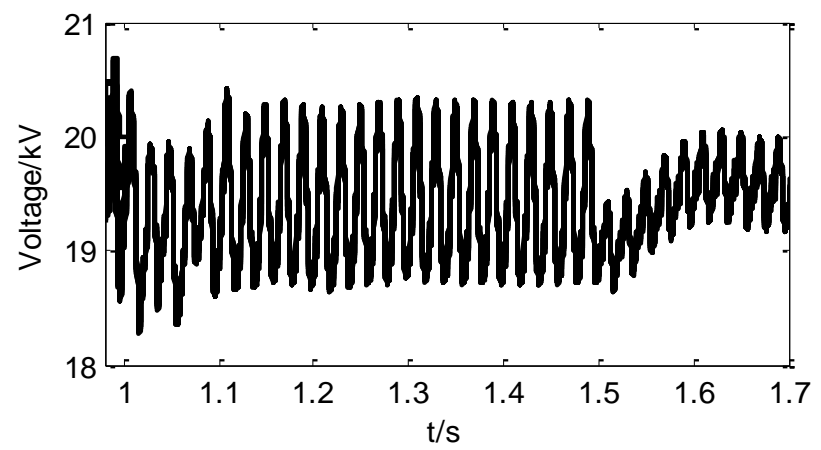

(c)

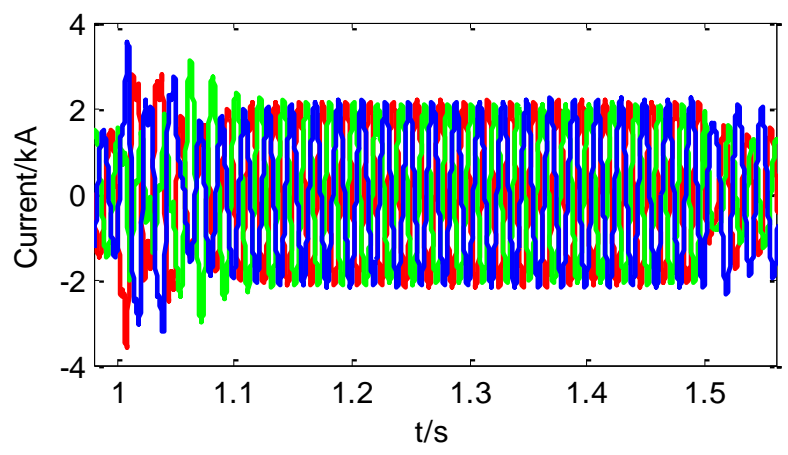

(e)

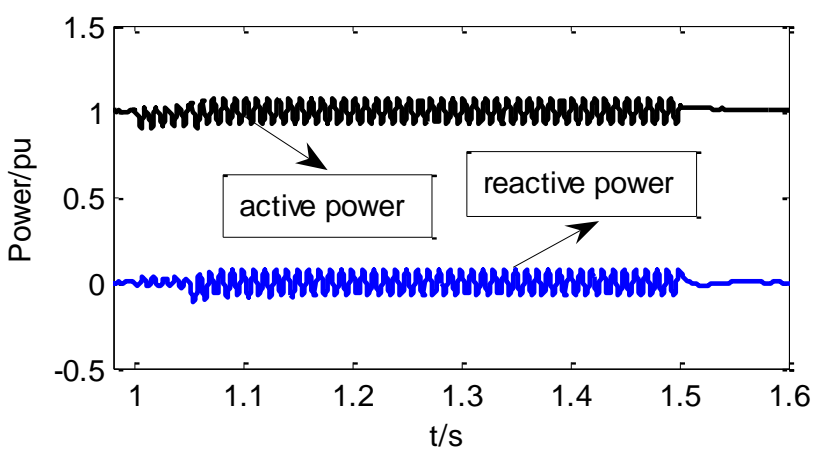

(b)

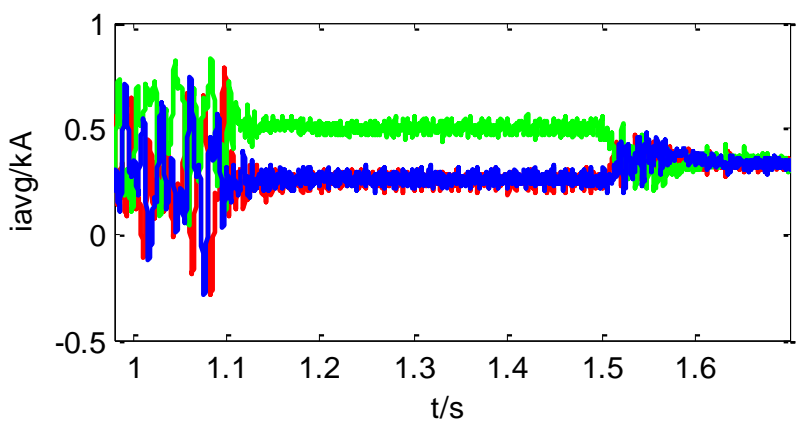

(d)

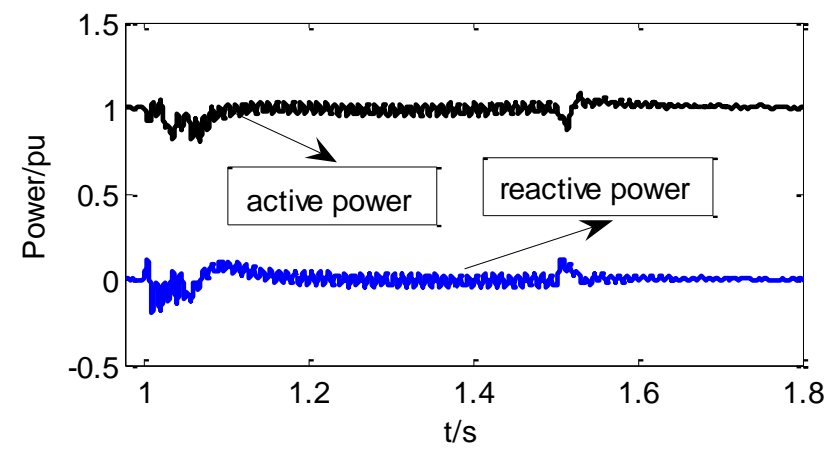

(f)

Fig.10. Waveform of control the negative sequence current: (a) three phase currents, (b) three phase active and reactive power, (c) capacitor voltages of SMs in the phase A upper arm, (d) three phase Iavg, (e) three phase currents with DVCC, (f) three phase active and reactive power with DVCC.

\subsubsection{Control Active Power Ripples}

Control strategy 2(without OCL) is firstly simulated in this case. As shown in Fig.11(a), the three phase active power ripples are eliminated, while reactive power ripples remain. Because the amplitude of arm 
currents becomes higher under unchanged power reference and the effect of negative sequence current, capacitor ripples in Fig.11(c) are also larger than that in Fig.10(c). It should be paid attention to current of phase A, the current amplitudes in Fig.11 (b) is larger than that in Fig.10 (a), which means severe over current problem, and may cause damage to the electric devices if fault lasts long. As shown in Fig.11(d), the circulating current components are also suppressed under this condition. Because the three phase ac active power is approximately balanced in this case, unlike Fig.10(d), the three phase $I_{\text {avg }}$ are almost equal with each other. It can be seen from Fig.11(e) (f) that the active ripples can be also suppressed under DVCC, but the control effect is somewhat different from PR controller because of the same reason of negative sequence current control.

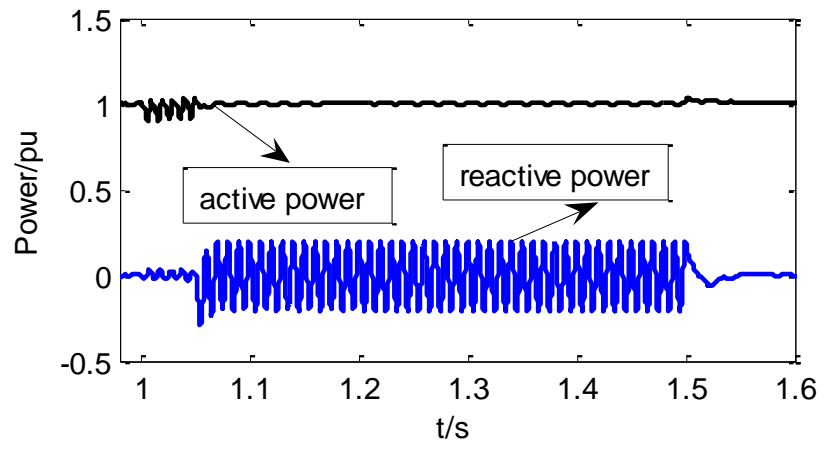

(a)

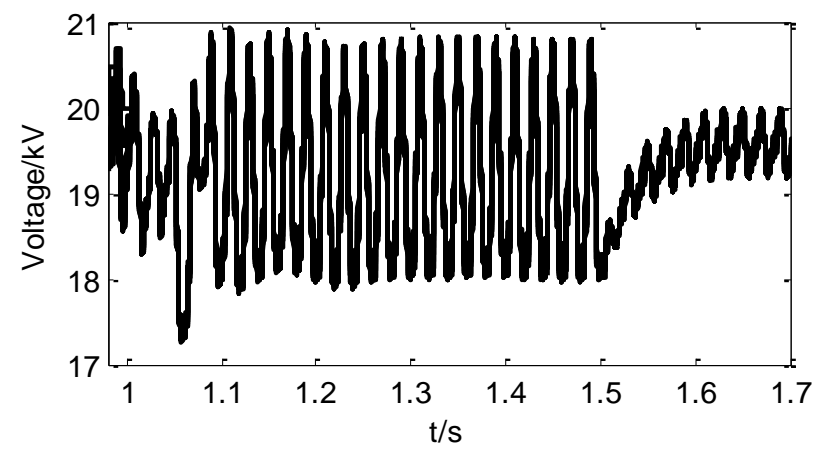

(c)

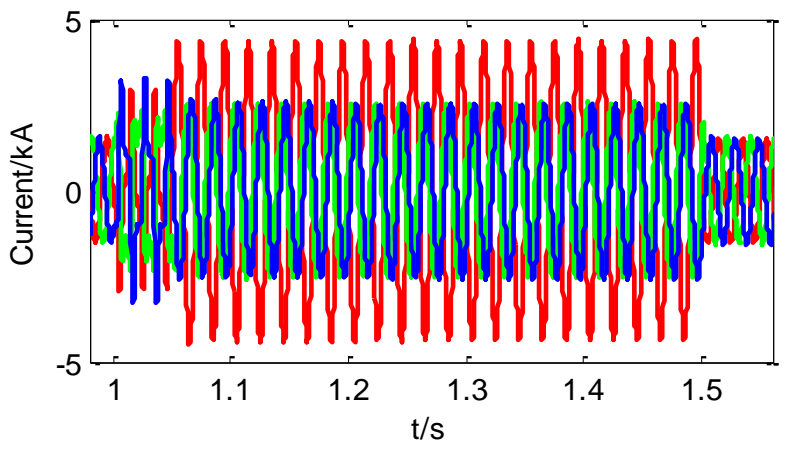

(b)

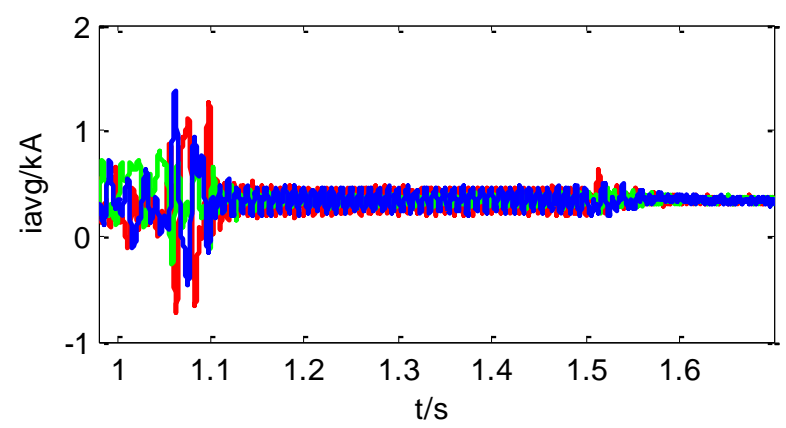

(d) 


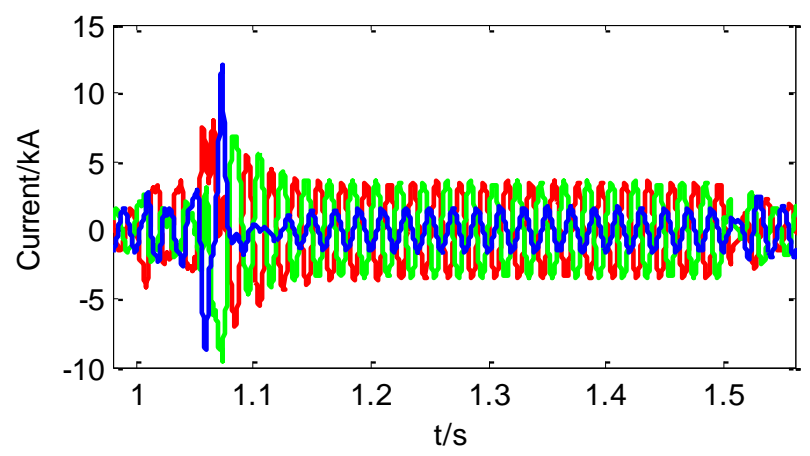

(e)

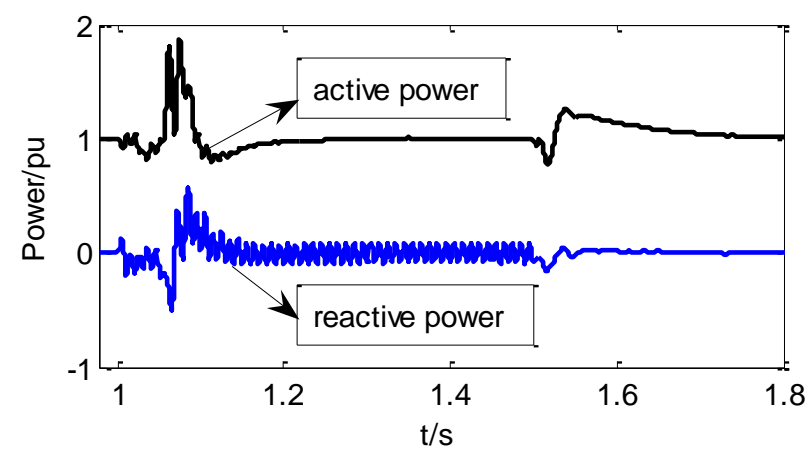

(f)

Fig.11. Waveform of control the active power ripple: (a) three phase active and reactive power, (b) three phase currents, (c) capacitor voltages of SMs in the phase A upper arm, (d) three phase Iavg, (e) three phase currents with DVCC, (f) three phase active and reactive power with DVCC.

The following simulation is conducted with OCL. Active power command is adjusted automatically to less over current degree according to the $\eta$ and $k$. The output active power reduces from $1 \mathrm{pu}$ to $0.5 \mathrm{pu}$ during fault as shown in Fig.12(a). The current amplitude of phase A in Fig.12(b) also decreases from about 5kA to $2.3 \mathrm{kA}(\rho=1.5$, compared with Fig.11(b)). Fig.12(c) shows that capacitor voltage ripples decrease accordingly under reduced transmitted active power. What is more, the three phase $I_{\text {avg }}$ in Fig.12(d) also decreases for the same reason.

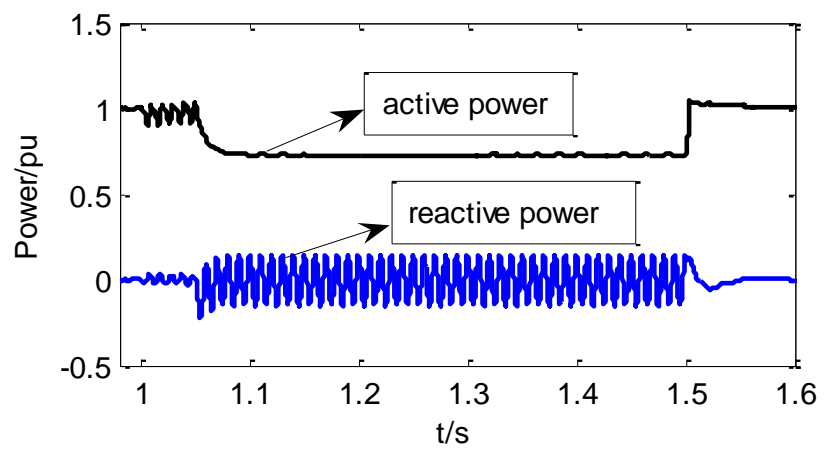

(a)

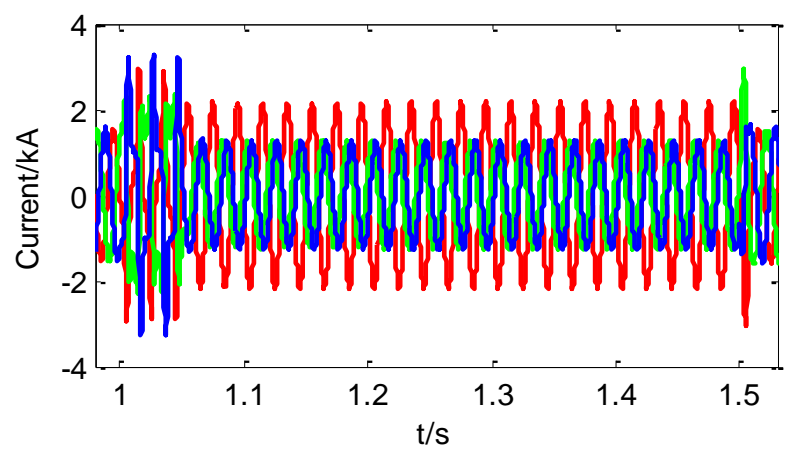

(b) 


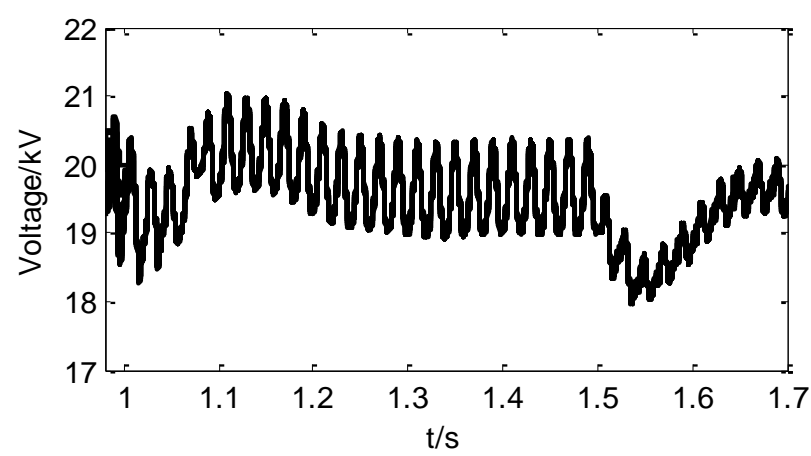

(c)

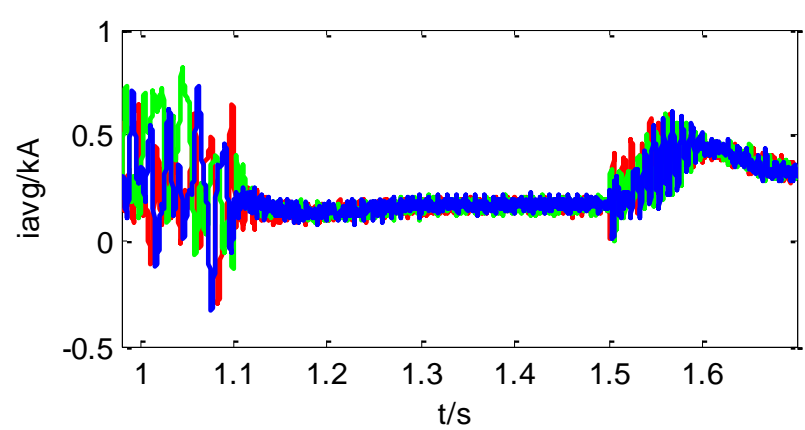

(d)

Fig.12. Waveform of control active power ripple under reduced active power command: (a) three phase active and reactive power, (b) three phase currents, (c) capacitor voltages of SMs in the phase A upper arm, (d) three phase Iavg .

\section{Conclusion}

This paper proposes a quasi-PR controller to control negative and positive current uniformly under unbalanced grid voltage conditions. The controller numbers are reduced half and the current extraction procedure is also avoided compared with the traditional DVCC. The sequence components of arm current and circulating current are analyzed under balanced and unbalanced voltage conditions by a more general method. A capacitor voltage balancing strategy for the HVDC system is also improved. The simulating results show that the quasi PR controller provides the desired controlling objects under unbalanced grid conditions.

\section{Acknowledgement}

This work was supported in part by the National Science Foundation of China under Grant 51177042, and in part by the National High Technology Research and Development Program of China(863 Program) (No.2013AA050105).

\section{References}

[1] solutionsEnrique Acha, Luis M. Castro. A generalized frame of reference for the incorporation of multi-terminal VSC-HVDC systems in power flow solutions. Electric Power Systems Research 2016;136: 415-424. 
[2] N. Flourentzou, V. G. Agelidis, and G. D. Demetriades, "VSC-based HVDC power transmission systems: An overview," IEEE Trans.,Power Electron s., vol. 24, no. 3, pp. 592-602, Mar. 2009.

[3] Vahid Rasouli Disfani, Lingling Fan, Zhixin Miao, Yan Ma. Fast model predictive control algorithms for fast-switching modular multilevel converters. Electric Power Systems Research 2015;129:105-113.

[4] A. Lesnicar and R.Marquardt, "An innovative modular multilevel converter topology suitable for a wide power range," in Proc. IEEE Power Tech Conf., Bologna, Italy, 2003, vol. 3, pp. 23-26.

[5] Abd Almula Gebree, Longya Xu. Power quality and total harmonic distortion response for MMC with increasing arm inductance based on closed loop-needless PID controller. Electric Power Systems Research 2016;133:281-291.

[6] M. Saeedifard and R. Iravani, "Dynamic performance of a modular multilevel back-to-back HVDC system," IEEE Trans. Power Del., vol.25, no. 4, pp. 2903-2912, Oct. 2010.

[7] Q.R.Tu, Z.Xu, and L.Xu, "Reduced switching-frequency modulation and circulating current suppression for modular multilevel converters," IEEE Trans. Power Del., vol. 26, no. 3, pp. 20092017, Jul. 2011.

[8] H.Akagi, "Classification, terminology, and application of the modular multilevel cascade converter (MMCC)," IEEE Trans. Power Electron., vol. 26, no. 11, pp. 3119-3130, Nov. 2011.

[9] Minyuan Guan Zheng Xu, "Modeling and Control of a Modular Multi level Converter-Based HVDC System Under Unbalanced Grid Conditions," IEEE Trans. Power Electron., vol. 27, no. 12, pp.48584868, Dec. 2012.

[10]Xiaoqian Li, Qiang Song, Wenhua Liu, "Protection of Nonpermanent Faults on DC Overhead Lines in MMC-Based HVDC Systems,” IEEE Trans. Power De l., vol. 28, no. 1, pp. 483-451,Jan 2013.

[11] M. Saeedifard, R. Iravani, and J. Pou, “A space vector modulation strategy for a back-to-back fivelevel HVDC converter system," IEEE Trans. Ind. Electron., vol. 56, no. 2, pp. 452-466, Feb. 2009. 
[12] Shaohua Li, Xiuli Wang, Zhiqing Yao, Tai Li, and Zhong Peng, "Circulating Current Suppressing Strategy for MMC-HVDC Based on Nonideal Proportional Resonant Controllers Under Unbalanced Grid Conditions," IEEE Trans. Power Electron., vol. 30, no. 1, pp. 387-397, Nov. 2015.

[13] Yuebin Zhou, Daozhuo Jiang, Jie GuoPengfeiHu, and Yiqiao Liang, "Analysis and Control of Modular Multilevel Converters Under Unbalanced Conditions," IEEE Trans. Power Del., vol.28, no. 4, pp. 1986-1995, Oct. 2013.

[14] H. Pengfei, J. Daozhuo, Z. Yuebin, G. Jie, and L. Zhiyong, "Study of the proportional resonant control based modular multilevel converter,” in Proc. 3rd Int. Conf. Int. Conf. Digital Manuf. Autom., 2012, pp. 810-813.

[15]I.Etxeberria, U,Viscarret, M.Caballero, A.Rufer, S.Bacha, "New Optimized PWM VSC Control Structures and strategies Under Unbalanced Voltage transients", IEEE Trans. on Industrial Electronics., Vol. 54, No. 5, October 2007, pp. 2902-2914.

[16] Q. Tu, Z. Xu, and J. Zhang, "Circulating current suppressing controller in modular multilevel converter," in Proc. IEEE 36th Annu. Conf. Ind.Electron. Soc., 2010, pp. 3198-3202.

[17] J.W. Moon, C. S. Kim, J.W. Park,D.W.Kang, and J.M.Kim, "Circulating current control inMMCunder the unbalanced voltage," IEEE Trans.Power Del., vol. 28, no. 3, pp. 1952-1959, Jul. 2013.

[18] Qiang Song, Wenhua Liu, Xiaoqian Li ,el al, "A Steady-State Analysis Method for a Modular Multilevel Converter," IEEE Trans. Power Electron., vol. 28, no. 3, pp. 3702-3713, Aug. 2013.

[19] Kalle Ilves, Antonios Antonopoulos, Staffan Norrga, el al, "Steady-State Analysis of Interaction Between Harmonic Components of Arm and Line Quantities of Modular Multilevel Converters," IEEE Trans. Power Electron., vol. 27, no. 1, pp. 57-68, Jan. 2012.

[20] M. Glinka and R. Marquardt, "A new AC/AC multilevel converter family," IEEE Trans. Ind. Electron., vol. 52, no. 3, pp. 662-669, Jun.2005. 
[21] S. Rohner, S. Bernet, M. Hiller, and R. Sommer, "Modulation, losses, and semiconductor requirements of modular multilevel converters," IEEE Trans. Ind. Electron., vol. 57, no. 8, pp. 26332642, Aug. 2010.

[22] Changliang Xia, Faqiang Zhou, Zhiqiang Wang, and Xiangning He, "Equivalent Switch Circuit Model and Proportional Resonant Control for Triple Line-Voltage Cascaded Voltage-Source Converter," IEEE Trans. Power Electron., vol. 28, no. 5, pp.2389-2402, May. 2013.

[23] R.Teodorescu, F.Blaabjerg, M. Liserre, and P.C.Loh, "Proportional resonant controllers and filters for grid-connected voltage-source converters," IEEE Proc. Electric Power Appl., vol. 153, no. 5, pp. 201 209, Sep. 2006.

[24] Alejandro G. Yepes, Francisco D. Freijedo. "Analysis and Design of Resonant Current Controllers for Voltage-Source Converters by Means of Nyquist Diagrams and Sensitivity Function", IEEE Trans. Ind. Electron.,vol. 58, no11.pp:5231-5250 11, Nov.2011.

[25] Perez M, Rodrigu ez J, Pont J, et al. Power distribution in hybrid multi cell converter with nearest level modulation [C] MProc IEEE ISIE. Vigo, S pain: IEEE, 2007: 736-741.

[26] RODRIGU EZ J, LAI J S, PENG F Z, "Multi level inverters: a survey of topologies, controls, and applications”. IEEE Trans on Industrial Electronics, 2002, 49(4) : 724-738.

[27] M. Dommaschk, "Drive for a phase module branch of a multilevel converter," Int. Patent WO2008/086760A1, Jul. 24, 2008.

[28] Minyuan Guan, Zheng Xu, Hairong Chen. Control and modulation strategies for modular multilevel converter based HVDC system IECON 2011-37th Annual Conference on IEEE Industrial Electronics Society. Page(s): 849 - 854. 